\title{
LA HOMOGENEIDAD SIMBÓLICA DEL UNIVERSO FEMENINO EN LA NOVELA PEDRO PÁRAMO, DE JUAN RULFO
}

\author{
Jorge Murillo Medrano
}

\begin{abstract}
RESUMEN
En el siguiente trabajo se hace una interpretación simbólica del universo femenino de la novela Pedro Páramo, de Juan Rulfo, partiendo de la base de que Susana San Juan es el personaje principal y que las otras mujeres que aparecen en la trama son especializaciones de la sacralidad de ésta. Como fundamento teórico para la interpretación, se emplean las ideas de Mircea Eliade en relación con el pensamiento mítico-simbólico.
\end{abstract}

\begin{abstract}
This article proposes an interpretation of the feminine characters of Pedro Páramo, a novel written by Juan Rulfo. It is assumed that Susana San Juan is the main character, and the other women are seen as part of San Juan's sacredness. As a theoretical frame, Mircea Eliade's ideas about symbolism and myth are used.
\end{abstract}

Desde una perspectiva simbólica, resulta provechoso analizar el universo femenino de la novela Pedro Páramo, de Juan Rulfo, en la medida en que permite un acercamiento más totalizador de las actantes que aparecen en dicho texto. Por ello, hemos decidido plantear la hipótesis de que, lideradas por Susana San Juan, personaje principal de la novela ${ }^{1}$, las otras mujeres que aparecen constituyen una especialización simbólica de ella y que, por lo tanto, forman, junto con Susana, un solo personaje, desde la perspectiva mítico-simbólica propuesta por Mircea Eliade ${ }^{2}$.

Para llevar a cabo el análisis, se presenta, en primer lugar, una visión general del simbolismo del personaje Susana San Juan y luego se explica cómo cada una del resto de actantes femeninas representa una parte de ese simbolismo general apuntado.

\section{Susana San Juan: un símbolo}

En un estudio anterior (Murillo 1991), se planteó que Susana San Juan constituye, dentro de la novela Pedro Páramo, una triple estructura hierofánica (tierra, agua y luna); e incluso se demostró cómo ella misma conforma una hierofanía, al considerarla inmersa dentro de una realidad sacra. También se comprobó que, a pesar de que las simbologías de lo telúrico y lo 
acuático pueden deslindarse hasta cierto punto, su simbolismo último sólo puede descubrirse en la medida en que se visualice desde una perspectiva selénica.

No obstante, ante la multiplicidad hierofánica que ha arrojado la descripción de la mística lunar, resulta conveniente buscar una visión de conjunto que ponga de manifiesto la coherencia y complementariedad de todas esas hierofonías lunares de tal suerte que reúna y sintetice a la vez la totalidad hierofánica de la actante en estudio.

El mismo Eliade (1979, Cap. IV) proporciona esa perspectiva unitaria al observar que las hierofonías lunares pueden agruparse alrededor de cuatro núcleos básicos:

a) Fertilidad (aguas, vegetación, mujer; "antepasado" mítico)

b) Regeneración periódica (simbolismo de los animales lunares; "hombre nuevo", sobreviviente de una catástrofe acuática causada por la luna; muerte y resurrección iniciáticas, etc...)

c) Tiempo y destino (la luna mide, teje los destinos y enlaza entre sí planos cósmicos heterogéneos)

d) Cambio, marcado por la oposición luz-oscuridad (mundo superior-mundo inferior, etc...)

Se puede, entonces, aseverar que el primer estatuto isotópico que Susana San Juan recubre es precisamente el de la fertilidad. Su identificación y asimilación con la Tellus Mater la hace aparecer como la madre por excelencia, la generadora de toda vida para Comala. El aniquilamiento y la desaparición de toda práctica agrícola en el valle de este pueblo está subordinado y marcado por el devenir selénico de esta actante, pues recuérdese que la fertilidad de la tierra depende, en última instancia, de los ciclos o fases lunares.

Por otro lado, también se hace patente la intrínseca relación entre Susana y las aguas. Toda vez que en el desarrollo diegético se presenta ya sea el recuerdo que Páramo conserva de ella o bien una microsecuencia en la que ella participa como figura central, se hace inminente la presencia de lo líquido en cualesquiera de sus variantes: lluvia, brisa, rocío e inclusive humedad. Ella misma, además, se identifica y equipara con el principio acuático en la medida en que se reintegra al océano primordial; esta asimilación la hace adquirir el estatus de Genetrix Universal ya que en el simbolismo de las aguas se resumen todas las posibilidades de existencia.

La consideración de Susana como un antepasado mítico puede hacerse guardando siempre las reservas del caso. Se sabe bien que ella no es la primera habitante de Comala; pero al menos en la parte de la historia del pueblo que presenta la novela, Susana sí se constituye en un eje estructurante. El pueblo entero depende de Páramo, de lo que se dicte en La Media Luna; pero, a su vez, tanto Páramo como la misma Media Luna tienen su explicación y su justificación en la figura de la San Juan. Si Páramo ha sostenido su hacienda y, por ende, la vida de Comala, es porque todo lo ha preparado para ella; porque todo, en resumidas cuentas, le pertenece y encuentra en ella su sentido último.

Se puede decir, entonces, que ella es un antepasado mítico en tanto funciona como una fuerza motriz de la cual depende la existencia de Comala, es decir, actúa como principio fértil que genera toda posibilidad de vida.

En cuanto a la regeneración periódica, Susana se proyecta dentro del texto como el principio regenerativo por excelencia. En primera instancia, ella misma debe experimentar 
una muerte y una resurrección iniciáticas ${ }^{3}$ con el objetivo de regenerarse espiritualmente; el simbolismo de renovación y purificación de esta muerte iniciática queda muy bien expresado en su inmersión repetida a las aguas oceánicas puesto que todo lo que se reintegra a las aguas primordiales es "disuelto", es "abolido" para que pueda nacer de nuevo, convertirse en un "hombre nuevo".

La muerte simbólica de esta actante es también proyectada a un nivel cósmico (en forma de diluvio) para el resto del pueblo de Comala. No obstante, tanto la práctica de inmersión de Susana como el diluvio que sepulta a Comala tienen la misma función soteriológica y renovadora: se disuelven las formas viejas y agotadas, la "humanidad vieja", para dar lugar a la aparición de una nueva era dominada asimismo por hombres nuevos.

De esta manera, Susana se regenera a sí misma, pero también posibilita una renovación del pueblo, simbólicamente, de la humanidad. El término del diluvio en Comala coincide perfectamente con su salida de las tinieblas de la muerte iniciática y, por lo tanto, habiendo adquirido ya su condición de iniciada, de "mujer nueva", ella deviene en figura axiológica para la nueva historia de Comala. Ella es la purificada por el poder de las aguas y, por ello, le corresponde también ser la fundadora de una nueva era, un nuevo periodo que rebasa los límites temporales y espaciales impuestos por el devenir histórico.

Las consideraciones anteriores permiten asegurar, asimismo, que Susana San Juan, al asimilarse a la luna, se presenta como la regidora de destino para los habitantes del lugar; ella mide y teje sus destinos. Al haber superado su condición de neófita, después de transitar por el laberinto de la muerte simbólica -lo que la acredita como una privilegiada-, ella se convierte en una figura soteriológica que conduce al pueblo hacia un espacio y un tiempo sagrados. La historia de Comala queda abolida en un plano humano ya que tanto Susana como el pueblo por completo han sido reintegrados al Caos Primordial (han sido sumergidos en las aguas) para comenzar, de esta manera, una nueva vida.

Este recomienzo se da en un nuevo espacio definido en términos de un acceso a las diferentes regiones cósmicas (Cielo-Purgatorio-Tierra) y en un tiempo reversible y circular: los habitantes de Comala estarán eternamente, al igual que Susana-Luna, yéndose y volviendo, es decir, vivirán en un eterno retorno. En síntesis, una vez que Susana adquiere su condición de iniciada, se posibilita y le posibilita al pueblo el acceso a un espacio y un tiempo consagrados.

En relación con esto, señala Eliade (1979: 364):

\begin{abstract}
Al deseo de encontrarse perpetua y espontáneamente en un espacio sagrado responde el deseo de vivir perpetuamente, gracias a la repetición de los gestos arquetípicos, en la eternidad. La repetición de los arquetipos acusa el deseo paradójico de realizar una forma ideal (=el arquetipo) en la condición misma de la existencia humana, de encontrarse en la duración sin tener que llevar su fardo, es decir sin sufrir su irreversibilidad. Semejante deseo, observémoslo, no podría interpretarse como una actitud "espiritualista" para la cual la existencia terrestre, con todo lo que implica, sería desvalorizada en provecho de una "espiritualidad" de despego al mundo. Todo lo contrario, lo que podríamos llamar la "nostalgia de la eternidad" da testimonio de que el hombre aspira a un paraíso concreto y cree que la conquista de ese paraíso es realizable aquí abajo, en la tierra, y ahora, en el instante presente.
\end{abstract}

Por ello, a pesar de que tanto Susana como Comala tienen acceso a un espacio y un tiempo consagrados, siguen estando presentes en el escenario del pueblo y es allí, precisamente, viviendo como almas en pena, donde los encuentra Juan Preciado cuando llega al lugar. 
Habida cuenta de todo lo anterior, la explicación del último núcleo básico de significación, el cambio, resulta más transparente. Este cambio está definido básicamente por el binomio luz-oscuridad, el cual se encuentra en estrecha correlación con los de mundo superiormundo inferior, ser-no ser y vida-muerte. Susana, al igual que la luna, ha experimentado estos cambios; su devenir selénico está definido por estos dualismos.

Desde la perspectiva de Eliade $(1974)^{4}$, el símbolo es entendido como clave fundamental del pensamiento mítico ya que el proceso simbólico trasciende la hierofanización para proyectarse como una dimensión totalizadora, más integradora; de este modo, el símbolo prolonga la hierofanía recubriendo otros niveles consagrados que le son afines e inherentes.

Una de las características primordiales del símbolo es la simultaneidad de sentidos que revela; aúna, bajo un mismo significante (simbolizante), un complejo haz de significaciones entre las cuales, bajo el disfraz de una aparente contradicción, se descubre una coherencia perfecta. Con el proceso simbólico se aclaran más las articulaciones del pensamiento mítico, pero que el símbolo asimila, identifica en su esencia misma, realidades que ante la vista del hombre profano parecen irreconciliables.

Según Eliade (1979: 402-3), "el díptico luz-oscuridad, por ejemplo, simboliza al mismo tiempo "el día y la noche" cósmicos, la aparición y desaparición de una forma cualquiera, la muerte y la resurrección, la creación y la disolución del cosmos, lo virtual y lo manifiesto, etc..." En este sentido se puede hablar de Susana San Juan como un símbolo, pues aún más allá de la hierofanización, en un nivel más profundo, ella despliega una compleja simbología.

Como se puede colegir de toda la descripción hierofánica realizada, la configuración actancial de Susana se articula sobre la base de aparentes oposiciones. En primer lugar, al identificarla con la Tellus Mater y con las aguas primordiales, se le adjudica un carácter de plena fertilidad; sin embargo, no se encuentra, en el texto, indicio alguno que haga evidente ese carácter fértil. En otros términos, podríamos decir que la San Juan se nos presenta, en forma simultánea, como fértil y no-fértil.

Esta conjunción de los contrarios (esta coincidentia oppositorum) sólo se hace posible y se justifica a la luz de la estructura simbólica. El símbolo tiende a unificar planos diversos y heterogéneos y a presentarlos como una totalidad, es decir, tiende a englobar los aspectos y no a separarlos. De ahí que se justifique también el porqué de la identificación entre Susana y la Virgen María. La Inmaculada Concepción (nótese la conjunción de los contrarios) remite, simultáneamente, a la Virgen Inmaculada, sin mancha ni pecado, y a la Madre por excelencia. Tanto Susana como la Virgen son castas, pero a la vez son la mejor alegoría de la Madre Universal.

Por otra parte, al presentarse Susana como un símbolo, logra superar su condición fragmentaria para proyectarse como una totalidad, como un ser que ha llegado a la plenitud. Por eso, después de su infancia, ella debe experimentar una muerte iniciática (debe superar el tránsito de la vida y la muerte) para aparecer en su evolución total. El día en que tiene acceso a esa condición de privilegiada es precisamente el 8 de diciembre (día de la Inmaculada Concepción) lo que indica que ella ha rebasado los opuestos, lo fragmentario, para presentarse ahora como una realidad acabada.

El experimentar una muerte iniciática (tanto en el nivel telúrico como en el acuático) le permite conocer profundamente lo que significa pasar de la vida a la muerte, del mundo superior al mundo inferior, del Cosmos al Caos; pero este tránsito también le permite superar 
esas dualidades y alcanzar, de este modo, la perennidad. A la vez, junto con ella, todo el pueblo de Comala debe experimentar una muerte iniciática (entendida aquí en el nivel cósmico: el diluvio) para poder renacer como una humanidad nueva.

De este modo, Susana San Juan (y, por consiguiente, el pueblo de Comala) vence las dualidades luz-oscuridad, día y noche cósmicos, creación y disolución del cosmos, lo virtual (las aguas, las profundidades ctonianas) y las formas (lo manifiesto), para aparecer finalmente como un verdadero símbolo de la vida y la muerte.

\section{Susana San Juan: el nomen o el omen}

El abordar a la San Juan a partir de sus componentes onomásticos permite corroborar también cómo en su nombre se visualiza esa misma sacralidad en la que se ha venido insertando a través de la presente lectura, pues en los términos que lo constituyen se registran intertextos bíblicos.

Dos son las referencias específicas que se registran en el texto bíblico en relación con este nombre: la primera se encuentra en el capítulo XIII del Libro de Daniel (*); la segunda, en los primeros tres versículos del capítulo octavo del Evangelio de San Lucas. De estas, de acuerdo con la lectura propuesta, conviene detenerse en el intertexto del evangelista Lucas, según el cual:

1. Algún tiempo después andaba Jesús por las ciudades y aldeas predicando, y anunciando el reino de Dios, acompañado de los doce,

2. y de algunas mujeres que habían sido libradas de los espíritus malignos y curadas de varias enfermedades, de María, por sobrenombre Magdalena, de la cual había echado siete demonios,

3. y de Juana, mujer de Cusa, mayordomo del rey Herodes, y de Susana, y de muchas otras que le asistían con sus bienes.

De aquí, conviene hacer énfasis en el carácter inmaculado (purificado) que tipifica a esta mujer que acompaña a Jesús. Ella ha sido librada de los demonios (de lo pecaminoso) e inicia, de este modo, una nueva vida caracterizada por su sacralidad. En este sentido, su relación con la San Juan queda explícita, puesto que ya ha sido develado en qué medida esta actante de la novela Pedro Páramo se presenta, al final de la diégesis, como un ente renovado y purificado espiritualmente. Las dos adquieren, entonces, una nueva dimensión (una nueva vida) por la intervención de agentes purificadores y sagrados: Cristo y las aguas, respectivamente, agentes estos que actúan en las mismas coordenadas, pues recuérdese que, en última instancia, su función básica se define por el poder soteriológico.

De la variada gama de personajes que aparecen dentro del texto bíblico con este nombre, se trabajará en esta parte haciendo referencia específica al Bautista. En el Evangelio de San Lucas se presenta, en los primeros capítulos, una sinopsis de todo lo relacionado con la aparición del Bautista. Termina el evangelista esta reseña sobre la infancia de San Juan anotando: "80. Mientras tanto el niño iba creciendo, y se fortalecía en el espíritu, y habitó en los desiertos hasta el tiempo en que debía darse a conocer en Israel." 
Luego, aparece el Bautista predicando y bautizando en las orillas de Jordán. Con su bautismo en las aguas, San Juan no hace sino preparar al pueblo de Israel para el advenimiento del Mesías, quien cumplirá su misión escatológica no solo por medio del agua, sino que también por medio del espíritu. De esta manera, la predicación del Bautista está marcada plenamente por un sentido escatológico.

A la luz de la hierofanía acuática en la que Susana se inserta, es posible explicar el porqué de este lexema dentro de su nombre. Ella, del mismo modo que Juan el Bautista, remite a lo acuático como principio renovador y purificador. Esta función soteriológica de las aguas ha sido experimentada, en primer lugar, por ella misma en su inmersión a las aguas oceánicas y, en otra instancia, ella, al identificarse con la luna, provoca que todo Comala sea renovado por medio de un diluvio; es decir, que el pueblo experimente, en términos simbólicos, un bautismo. De modo manifiesto, la asociación intertextual que se entabla en el lexema San Juan queda muy bien explicitada a la luz del simbolismo de la hierofanía acuática a partir de la cual se configura esta actante.

Si se enfoca el nombre de esta actante a la luz de su relación sintagmática, se puede descubrir cómo en él se articulan, también, dos principios opuestos: lo femenino y lo masculino. Una vez más, hay que acotar que esta integración de los opuestos (esta coincidentia oppositorum) solo es posible explicarla en la medida en que se visualice a Susana haciendo referencia a la función unificadora de su simbolismo. Ella es, en última instancia, una totalidad que ha superado todos los opuestos, incluso el principio de diferenciación masculino-femenino. Por ello, es lícito referirse a Susana en términos de su carácter sacro y numinoso, entendiéndola precisamente como un ente divino que ha logrado despojarse de cualquier fragmentación que hubiera podido imponerle la dimensión de lo humano.

De ahí, entonces, que se pueda afirmar, asimismo, que una breve reflexión sobre los componentes onomásticos de la San Juan conduzca a la aseveración de que en su nomen (o numen) se manifiesta todo un trayecto de sentido que la gramática de producción textual su(im)pone; que más que nomen, lo que se pone en juego es un omen, todo un presagio que se despliega en el nivel de lo presupuesto.

\section{La homogeneidad en el universo femenino de la novela}

Partiendo de lo que ha sido expuesto y proyectando esas reflexiones al mundo femenino total que conforma la novela, se puede afirmar que, en realidad, en la figura de Susana San Juan se sintetizan, de manera conjunta y coherente, los atributos particulares de todas las mujeres que aparecen en la diégesis de la novela. En otros términos, que cada una de las mujeres de Comala no son sino fragmentos, parcelaciones de la totalidad que tipifica, per se, a la San Juan. Véase cómo se corrobora tal afirmación.

\subsection{Damiana Cisneros}

En cierto momento de la narración, esta actante es identificada con la luna. Una noche, cuando Páramo llega a buscarla con intenciones de poseerla -recuérdese que ella vivía en 
la Media Luna, pues era la caporala del lugar- opta por esconderse y relegarse en su habitación. La misma acción había sido ejecutada por la luna minutos antes:

Faltaba mucho por el amanecer. El cielo estaba lleno de estrellas, gordas, hinchadas de tanta noche. La luna había salido un rato y luego se había ido. Era una de esas lunas tristes que nadie mira, a las que nadie hace caso. Estuvo un rato allí desfigurada, sin dar ninguna luz, y después fue a esconderse detrás de los cerros. Lejos, perdido en la oscuridad, se oía el bramido de los toros ${ }^{5}$.

De este modo, dentro de la simbología de la narración, Damiana Cisneros acciona del mismo modo que la luna y Páramo, por su parte, es identificado con el toro, animal asociado con el principio fecundador.

\subsection{Dolores Preciado}

Su relación con la luna también se hace evidente. Cuando Páramo, con el objeto de saldar las deudas contraídas con la familia Preciado, manda, por intermedio de Fulgor Sedano, a pedir la mano de la "Lola", ella acepta complacida. El único inconveniente que se interpone para que el matrimonio se realice con la premura que Páramo desea es la influencia que la luna ejerce sobre el cuerpo de Dolores. En el coloquio suscitado entre Fulgor y la Preciado así se hace constar:

\footnotetext{
-Él quisiera que fuera ahora mismo. Si es por los ajustes, nosotros se los proporcionamos. La difunta madre de don Pedro espera que usted vista sus ropas. En la familia existe esa costumbre.

-Pero además hay algo para estos días. Cosas de mujeres, sabe usted. ¡Oh!, cuánta vergüenza me da decirle esto, don Fulgor. Me hace usted que se me vayan los colores. Me toca la luna. ¡Oh! que vergüenza." (El subrayado es nuestro.)
}

En palabras de Dolores, se puede apreciar cómo la mujer actúa regida por el devenir, el tiempo marcado por el astro selénico y en qué medida su accionar está supeditado y justificado por la mística lunar.

\subsection{Dorotea y Eduvigis Dyada}

Estas dos figuras se articulan sobre el binomio fértil-infértil, en un proceso de conjunción-disjunción propio del pensamiento simbólico. Dorotea representa, en grado absoluto, la imposibilidad de ser fértil. Ha pasado toda una vida vagando por el pueblo de Comala en busca de su anhelado hijo y jamás logra encontrarlo. Posteriormente, estando enterrada junto a Juan Preciado y al relatarle cómo fue decayendo la opulencia del pueblo, ella le narra la magnitud de su desgracia:

En el cielo me dijeron que se habían equivocado conmigo., Que me habían dado un corazón de madre, pero un seno de una cualquiera. Ese fue el otro sueño que tuve. Llegué al cielo y me asomé a ver si entre los ángeles reconocía la cara de mi hijo. Y nada. Todas las caras eran iguales, hechas con el mismo molde. Entonces pregunté. Uno de aquellos santos se me acercó y, sin decirme nada, hundió una de sus manos en mi estómago como si la hubiera hundido en un montón de cera. Al sacarla me enseñó algo así como una cáscara de nuez: "Esto prueba lo que te demuestra". 
Por otra parte, según le informa el arriero Abundio a Juan Preciado, antes de que este último llegue a Comala, Eduvigis Dyada es la dueña de la posada del pueblo y es allí donde él debe buscar hospedaje. Cuando Preciado llega al lugar indicado, Eduvigis le cuenta gran parte de su vida y de su amistad íntima con Dolores Preciado.

No obstante, de esta figura femenina interesa destacar su carácter inminentemente fértil. En diametral oposición a Dorotea, ella se caracteriza por su abundante progenie. Así lo confirma su hermana, María Dyada, en conversación sostenida con el padre Rentería:

\begin{abstract}
-Ella sirvió siempre a sus semejantes. Les dio todo lo que tuvo. Hasta les dio un hijo, a todos. Y se los puso enfrente para que alguien lo reconociera como suyo; pero nadie lo quiso hacer. Entonces les dijo: "En ese caso yo soy también su padre, aunque por casualidad haya sido su madre". Abusaron de su hospitalidad por esa bondad suya de no querer ofenderlos ni de malquistarse con ninguno.
\end{abstract}

\title{
3.4. La madre de Pedro Páramo
}

De la madre de Pedro Páramo se tiene referencia en algunas microsecuencias de la novela, cuando este actante evoca las épocas de su infancia. En la mente de Páramo, la imagen de su madre coincide plenamente con el retrato de una virgen:

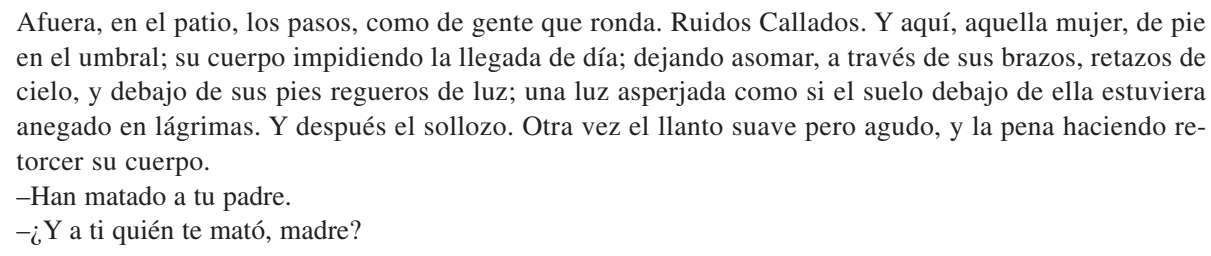

Dentro de este marco de referencia, se vuelve a insistir en la necesidad de interpretar a la progenitora de Páramo en tanto símbolo, ya que en ella se sintetiza el eterno binomio de la Virgen y madre. Por otra parte, su identificación con el elemento líquido, en su variante de lágrimas, se hace patente dentro del corte sintagmático transcrito. Esta misma asociación con la figura de la Virgen y de las aguas se descubre en otra microsecuencia de las diégesis:

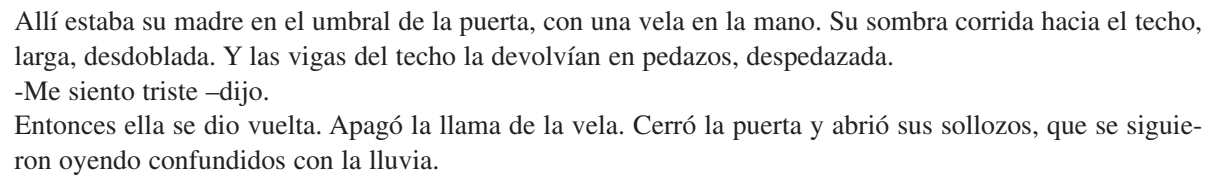

\subsection{La hermana de Donis: una mujer hecha de tierra}

Después de vagar por el ambiente fantasmal de Comala, Juan Preciado llega a la casa de Donis y su hermana, una pareja que vive en relación incestuosa. Preciado, poco antes de morir, vive sus últimos momentos en compañía de estos hermanos. La sensación nocturna que Preciado refiere de esta mujer expresa muy bien la plena identificación entre ella y la tierra: 


\footnotetext{
El calor me hizo despertar al filo de la medianoche. Y el sudor. El cuerpo de aquella mujer hecho de tierra, se desbarataba como si estuviera derritiéndose en un charco de lodo. Yo me sentía nadar entre el sudor que chorreaba de ella y me faltó el aire que se necesita para respirar. Entonces me levanté. La mujer dormía. De su boca borbotaba un ruido de burbujas muy parecido al de estertor.
}

Como se advierte, además de equipararse con lo telúrico, esta actante se asocia con el elemento líquido. La textura de su cuerpo "hecho de tierra" se ve modificada por la presencia del agua, cuya manifestación se da por medio del sudor.

\section{A modo de resumen}

Por ello, como se puede colegir de todas las observaciones anotadas, cada una de las mujeres de Comala constituye solamente una parcelación de la conformación conjunta que caracteriza a la San Juan. Damiana Cisneros y Dolores Preciado evidencian una hierofanización selénica: ambas están regidas por los movimientos de este astro. En otra instancia, tanto Eduvigis Dyada como Dorotea son susceptibles de ser concebidas como un símbolo femenino, puesto que encarnan la polaridad fértil-no fértil, respectivamente. Este díptico, a su vez, está sintetizado en la figura de la madre de Páramo, representación del eterno binomio Virgen y Madre. Por otro lado, la hermana de Donis se proyecta como representación primaria de la Tellus Mater, representación esta que se encuentra infiltrada por lo acuático. Lo líquido, asimismo, se registra como elemento constitutivo esencial en la configuración de la madre de Páramo.

Huelga observar, entonces, que cada una de estas mujeres posee una o dos de las caracterizaciones de Susana; o más bien, que en última instancia, dentro de la diégesis de la novela Pedro Páramo, todas las mujeres se proyectan como una sola que tiene su expresión máxima en la figura de Susana San Juan.

\section{Notas}

1. En otro trabajo (Murillo 1991) he propuesto que el personaje Susana San Juan debe ser considerado como el principal en la trama de la novela, siguiendo las pistas de lectura propuestas por autores como Bastos y Molloy (1978), Gutiérrez Mota (1985), Rodríguez (1972) y Valencia Solanilla (1984) y contraviniendo la lectura tradicionalmente masculina (desde el personaje Pedro Páramo) que ha guiado no sólo el título de la novela sino la crítica literaria en torno a las novelas sobre la figura del dictador en Hispanomérica.

2. El pensamiento de Mircea Eliade se halla diseminado en varios textos. Para tener una visión de conjunto de su propuesta, debe hacerse lectura obligatoria de ellos, especialmente del Tratado de Historia de las religiones. Para este trabajo, se han empleado como fuente los que aparecen en la bibliografía: 1961, 1967, 1972, 1973, 1974 y 1979.

3. Para una mejor comprensión de la interpretación de la muerte iniciática de Susana San Juan en términos de lo acuático (la inmersión en las aguas oceánicas y el diluvio), lo telúrico (la bajada a la cueva en busca de monedas de oro, por orden de su padre, Bartolomé San Juan) y lo selénico (la identificación de Susana con la luna) véase el análisis de este mismo autor (1991). 
4. Compárese también con lo expuesto por Cirlot (1978) y Chevalier y Gheerbrant (1982) en el apartado correspondiente a la definición de símbolo.

* Según nota acuñada por los exégetas bíblicos, este capítulo no se lee en el texto hebreo original sino que más bien ha sido trasladado de la versión griega de Teodoción.

5. A partir de esta cita, todas las demás se toman de la tercera edición de la novela, editorial Bruguera, Barcelona, España, 1984.

\section{Bibliografía}

Bastos, María Luisa y Silvia Molloy. 1978. "El personaje de Susana San Juan: clave de enunciación y de enunciados en "Pedro Páramo". En: Hispanoamérica. Año VII (20).

Castro Pallares, Alfonso. 1985. Pedro Páramo. México, D.F.: Fernández Editores S.A.

Cirlot, Juan Eduardo. 1978. Diccionario de Símbolos. Madrid: Editorial Labor S.A.

Chevalier, Jean y Alain Gheerbrant. 1969. Dictionnaire des Symboles. Paris: Editions Robert S.A. et Editions Jupiter.

Gutiérrez Mouat, Ricardo. 1985. "Un personaje olvidado de Pedro Páramo" En: Revista Iberoamericana. $\mathrm{N}^{\mathrm{o}} 338-348$, Enero-Julio.

Eliade, Mircea. 1961. Mitos, Sueños y Misterios. Buenos Aires: Compañía General Fabril Editora.

1967. Lo Sagrado y lo Profano. Madrid: Ediciones Guadarrama.

1972. El Mito del Eterno Retorno. Madrid: Alianza Editorial.

1973. Mito y realidad. Madrid: Ediciones Guadarrama.

1974. Imágenes y símbolos. Madrid: Taurus Ediciones.

1979. Tratado de historia de las religiones. Tercera edición. México D.F.: Ediciones Era.

Murillo, Jorge. 1991. “Susana San Juan: un tríptico hierofánico”. En: Káñina. Revista de Artes y Letras de la Universidad de Costa Rica. Vol. XV (1 y 2): 107-120.

Pupo-Walker, Enrique. 1969. “Personajes y ambiente en Pedro Páramo” En: Cuadernos Americanos. 167 (6).

Rodríguez, Julio. 1972. “Algunas observaciones sobre el simbolismo de la relación entre Susana San Juan y Pedro Páramo” En: Cuadernos Hispanoamericanos. 90 (270). 
Rulfo, Juan. 1978. Antología Personal. Prólogo de Jorge Ruffinelli. México D.F.: Editorial Nueva Imagen.

1984. Pedro Páramo. Barcelona: Editorial Bruguera S.A.

Valencia Solanilla, César. 1984. "Juan Rulfo: Mito femenino e identidad cultural". En: Universitas Humanistica. 13 (22), Julio-Diciembre. 